\section{Scientific journal}

PHYSICAL AND MATHEMATICAL EDUCATION

Has been issued since 2013.

Науковий журнал

ФІЗИКО-МАТЕМАТИЧНА ОСВІТА

Видається $з 2013$.
ISSN 2413-158X (online)

ISSN 2413-1571 (print)

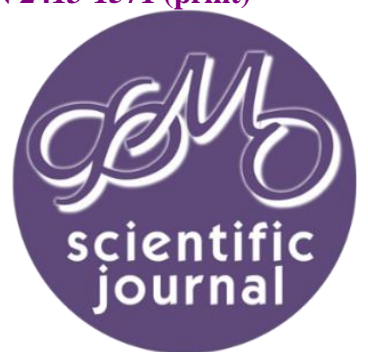

Асмыкович И.К., Пыжкова О.Н., Борковская И.М. Об опыте преподавания математики для инженерных специальностей в рамках дистанционного обучения. Фізико-математична освіта. 2021. Випуск 3(29). С. 31-36.

Asmykovich I., Pyzhkova O., Borkovskaya I. About the experience of teaching mathematics for engineering specialties in the framework of distance learning. Physical and Mathematical Education. 2021. Issue 3(29). P. 31-36.

DOI 10.31110/2413-1571-2021-029-3-005

УдК 378.147:512.5

И.к. Асмыкович

Белорусский государственный технологический университет, Беларусь asmik@tut.by

О.Н. Пыжкова

Белорусский государственный технологический университет, Беларусь olga.pyzhcova@gmail.com

И.М. Борковская

Белорусский государственный технологический университет, Беларусь borkovskaia@gmail.com

\title{
ОБ ОПЫТЕ ПРЕПОДАВАНИЯ МАТЕМАТИКИ ДЛЯ ИНЖЕНЕРНЫХ СПЕЦИАЛЬНОСТЕЙ В РАМКАХ ДИСТАНЦИОННОГО ОБУЧЕНИЯ
}

АННОТАЦИЯ

Формулировка проблемы. В статье обсуждается проблема обеспечения качества математического образования в современных условиях. Для решения этой проблемы необходимо совершенствовать как формы и методы преподавательской работы, так и организацию учебного процесса в целом. В настоящее время, когда преподавание осложняется проблемой соблюдения эпидемиологических требований в связи с распространением инфекции COVID-19, требуется оптимально использовать все возможности, чтобы обеспечить должный уровень математической подготовки будущих инженерных кадров.

материалы, методы. Для решения проблемы анализируется опыт преподавания математических дисииплин на кафедре высшей математики Белорусского государственного технологического университета с применением как традиционных, так и информационно-коммуникационных технологий. Использованы результаты опроса, проведенного среди студентов факультета технологии органических веществ БГТУ. Проанализированы современные публикации по дистанционному обучению математике.

Результаты. Проведен анализ состояния преподавания математики для студентов инженерных специальностей в Республике Беларусь. Изучен вопрос использования классических и информационно-коммуникационных образовательных технологий в современных условиях на примере преподавания математических дисциплин, а также возможностей онлайн обучения с использованием платформ LMS Moodle, Microsoft Teams, Zoom и др. Обсуждены недостатки и преимущества дистанционного обучения.

Выводы. Оптимальным для обеспечения качества математического образования в современных условиях является сочетание классических подходов в преподавании с использованием информационно-коммуникационных технологий. Степень усвоения знаний зависит не столько от формы преподнесения преподавателем материала, сколько от мотивации студента к изучению предмета. Необходимо прививать студентам навыки самообразования, самоорганизации, принятия самостоятельных решений, воспитывать у студентов стремление к саморазвитию. При онлайн обучении следует использовать все возможности обучения и налаживания обратной связи со студентами с целью сохранения качества образования в непростой эпидемиологический период.

КЛЮЧЕВЫЕ СЛОВА: математика, методика преподавания, классический подход, информационно-коммуникационные технологии.

\section{ВВЕДЕНИЕ}

Постановка проблемы. Среди масштабных социальных проектов, предложенных в последние годы обществоведами и политиками в качестве потенциальной модели устойчивого развития социума, выделяется проект «Цифровое общество». Его преимущества многие исследователи видят в том, что он органично вписывается в траекторию стратегического курса формирования экономических укладов пятого и шестого поколений, т.е. обеспечивает дальнейший технико-технологический прогресс общества.

(С) И.К. Асмыкович, О.Н. Пыжкова, И.М. Борковская, 2021. 
Указанный социальный проект получил поддержку и в Беларуси: указом президента Республики Беларусь от 7 мая 2020 года в качестве первого из шести приоритетных направлений научной, научно-технической и инновационной деятельности на 2021-2025 годы утверждены «Цифровые информационно-коммуникационные и междисциплинарные технологии, основанные на них производства: развитие информационного общества, электронного государства и цифровой экономики; математика и моделирование сложных функциональных систем (технологических, биологических, социальных)».

Но, к сожалению, в реальной действительности преподаванию математики, одной из основных дисциплин для фундаментального образования инженера XXI века в Республике Беларусь, да и в России тоже, наносятся все более существенные удары (Асмыкович \& Пыжкова, 2020). Закладывание основ математической культуры должно происходить в процессе школьного образования, а это возможно лишь в том случае, когда математике уделяется должная роль. Количество часов и качество преподавания, требования к знаниям ученика определяют в итоге уровень его математической подготовки. Являясь в дальнейшем базой для освоения математических дисциплин в университете, школьная подготовка играет значимую роль в дальнейшем образовании специалиста. Главной целью преподавания математических дисциплин в университете является обеспечение качества образования, и достижению этой цели должны способствовать как формы и методы преподавательской работы, так и поддержка организационная, в том числе количество часов, отводимых на математические дисциплины. В настоящее время, когда к проблемам имеющимся присоединилась проблема соблюдения эпидемиологических требований в связи с распространением инфекции COVID19, преподавателю приходится изыскивать все возможности, чтобы обеспечить должный уровень математической подготовки будущих инженерных кадров. В статье обобщается опыт работы преподавателей кафедры высшей математики Белорусского государственного университета в сложившихся непростых условиях, обсуждаются возможности дистанционного обучения для обеспечения качества подготовки студентов.

Анализ актуальных исследований. Современный этап развития высшей школы характеризуется возрастающей творческой активностью преподавателя. Во все времена высшая школа отличалась методикой учебной работы и степенью самостоятельности студентов, а целью учебного процесса являлось развитие способности обучающихся к непрерывному самообразованию, к стремлению пополнять и обновлять свои знания. Но 2020 год внес свои коррективы в методологию образования, возникла необходимость внедрения и активного использования информационнокоммуникационных технологий (ИКТ) в образовательный процесс в целом, так как появились трудности в применении классического подхода, где все занятия проводились в аудиториях. При этом большие надежды возлагались на электронное обучение, которое называли инновационным подходом (Гончарова, 2019). Но в течение последнего года, когда большая часть педагогов столкнулась с реальным переходом на дистанционную форму обучения, в связи с пандемией коронавируса, подтвердились существенные проблемы, которые имеются при электронном обучении математике (Асмыкович, 2019), (Пармузина, 2020). Основной проблемой, как отмечалось и ранее, стала (Тестов, 2018) проблема понимания.

Для организации удаленного обучения в Белорусском государственном технологическом университете (БГТУ) были использованы различные платформы и опыт коллег из других стран. Так, например, в Польше образовательные ресурсы размещают на сайтах вузов, в Чехии проводятся онлайн занятия, студентам предлагается разработка интерактивных рефератов по рассмотренным темам.

Опыт организации учебного процесса по математике показывает, что используемая кафедрой высшей математики БГТУ уровневая технология эффективна при решении задачи повышения качества математического образования и, как следствие, формирования исследовательской компетентности студента (Асмыкович., Борковская, Пыжкова, 2019).

Основной целью этой технологии является:

- организация самостоятельной работы студентов;

- пробуждение у студентов интереса к приобретению знаний;

- оказание помощи студенту в преодолении трудностей в учебе;

- ускорение процесса адаптации для студентов первых курсов в условиях обучения в вузе.

Уровневая образовательная технология применяется при проведении аудиторных занятий по математическим дисциплинам и является эффективным средством, обеспечивающим дифференцированный подход к студентам и учитывающим их личностные особенности. В современных условиях оказалось необходимым дополнить используемые методы и формы преподавания информационно-коммуникационными технологиями, дающими возможность проводить занятия в удаленном формате.

\section{МАТЕРИАЛЫ И МЕТОДЬ}

Конечно, дистанционное обучение появилось ещё в 18 веке, задолго до Интернета, а со временем изменялись лишь методы его организации. Это форма обучения, где взаимодействие педагога и обучаемого происходит на расстоянии, в частности, с помощью ИКТ. Есть сторонники версии, что такое обучение может полностью заменить традиционное. В ответ приведем пример: когда интенсивно начало развиваться телевидение, в США были активные сторонники предположения, что в ближайшем будущем телевидение заменит и лекции ведущих профессоров, и практические занятия. Но довольно быстро выяснилось, что эти теоретические построения весьма далеки от реальной действительности.

На наш взгляд, при использовании новых информационных технологий в преподавании в идеале каждый студент получает полный конспект лекций заранее в электронном или распечатанном виде и приходит на лекцию слушать ее осмысленно. Преподаватель с помощью презентаций обобщает и структурирует материал, объясняет сложные моменты. Благодаря компьютерным технологиям можно реализовать материал большего объема, а также выделить и детально пояснить главное содержание лекции, привести основные идеи и подходы, предложить материал для самостоятельного изучения по указываемой литературе, что, в целом, оживляет учебный процесс, делая его более динамичным и 
разнообразным (Асмыкович \& Ловенецкая, 2019). Но при этом самым существенным вопросом, особенно в преподавании математических дисциплин, остается вопрос достаточно хорошего понимания излагаемого материала и отработки техники использования при решении практических задач и использования математических моделей в курсах инженерных дисциплин.

При организации учебного процесса с применением ИКТ центр тяжести в обучении перемещается с преподавания посредством лекций и практических занятий (offline) на обучение online на платформах СдО на базе LMS Moodle, Microsoft Teams, Zoom и др., а также на самостоятельную работу студентов в освоении материала (Гончарова, 2019). Тем самым увеличивается интенсивность подготовки сотрудниками кафедры различных материалов для дистанционного обучения и для удаленного проведения занятий. При этом времени на подробное изучение той или иной платформы практически нет. Перед педагогами встали множество вопросов, среди которых, например, как выстроить систему дистанционного обучения, как контролировать процесс, как обеспечить усвоение учебного материала студентов, находящихся на карантине и т.п. Итак, как и во все времена, насущными остаются вопросы: «чему учим?», «как учим?» и «что в результате получаем?».

Важнейшим условием качественного онлайн обучения является, прежде всего, материально-техническое обеспечение учебного процесса и сверхскоростной интернет. В БГТУ на факультете технологии органических веществ было проведено анкетирование, в котором приняло участие 155 студентов. В анкете были предложены следующие вопросы:

1. Для дистанционного обучения (ДО) использовали

$\square$ свой ноутбук $\square$ свой смартфон

2. В чем Вы видите преимущества и недостатки занятий on-line по сравнению с традиционными аудиторными занятиями (лекции, практические занятия)

Преимущества

Недостатки

3. Вы предпочтете Лекции $\square$ on-line $\square$ off-line

Практические занятия $\square$ on-line $\square$ off-line

4. Какие факторы мешали Вам учиться дистанционно эффективно?

5. Какие платформы использовали? $\square$ СДО БГТУ $\square$ Teams $\square$ Zoom $\square$ Другую

6. Какая для Вас была наиболее эффективна? $\square$ СдО БГтУ $\square$ Teams $\square$ Zoom Почему? Сравните

7. Что, на Ваш взгляд, может повысить качество дистанционного обучения?

8. Ваши пожелания преподавателям.

Несмотря на то, что порядка 70 \% опрошенных студентов (в анкетировании приняло участие 155 студентов) имеют ноутбуки, основная их масса использует смартфоны для работы в СДО, у многих возникают проблемы технического характера (с подключением, со звуком и поддержкой возможностей образовательных платформ).

Система дистанционного обучения (СДО) БГТУ на основе LMS Moodle используется не один год, но на первом этапе внедрения в учебный процесс предоставляла новые возможности для организации традиционного обучения, совмещая очные с дистанционными дополнительными занятиями для мотивирования студентов. Были созданы эУМк по различным курсам, их материалы размещены в СДО, использовались интерактивные возможности системы, однако лишь малая часть студентов пользовалась данными материалами.

Переход лекций в online формат потребовал и времени, и введения новых технологий (Гараев \& Бабина 2020). Вначале лекции размещались в свободном доступе в СДО (LMS Moodle) для каждого потока, во время занятий по расписанию преподаватель вел чат-занятия, предварительно делав рассылку списка вопросов, используя элементы телеконференции. Но усвоение теоретического материала шло очень плохо. Доступность различных материалов в интернете для ответа на вопросы преподавателя не означает их нахождение, а тем более усвоение, полученная таким способом информация не сохраняется в памяти надолго. Со временем лекции стали проводиться почти в традиционном формате: в режиме видеоконференции в СДО или Microsoft Teams. Лектор излагал новый материал, задавал вопросы, поддерживал чат-занятия, при этом вопрос с посещением таких занятий, вернее сказать, с присутствием студентов на лекции, остается открытым. На вопросы о том, какое изложение материала более приемлемо, 54\% опрошенных студентов ответили: online лекции в Microsoft Teams. К преимуществам таких лекций студенты отнесли следующее:

- обучаться можно в любом месте (общежитии, дома, аудитории и т.п.);

- не нужно тратить время на проезд;

- возможность просмотреть запись лекции в любое удобное время.

К недостаткам:

- нет контроля со стороны преподавателя, а, следовательно, конспект лекций многие не пишут;

- недостаточная мотивация или ее отсутствие, тяжело заниматься, когда в одной комнате соседи либо спят, либо занимаются своими делами;

- из-за совмещений занятий online и offline часть лекций приходится пропускать.

Практические занятия проходили в штатном режиме для части студентов. Остальные же получали задания через систему дистанционного обучения. Ответы на задания должны были присылаться в заранее оговоренное время в форматах doc или jpg. На преподавателей, особенно ассистентов, легла слишком большая нагрузка по проверке заданий, они делали свои пометки и отсылали исправленные файлы обратно студентам, при этом консультировали студентов в различных мессенджерах.

В связи с эпидемиологической обстановкой во второй половине семестра часть практических занятий проходили online, а контрольные мероприятия и лабораторные занятия в университете. При этом провести 3-4 пары по расписанию перед экраном компьютера оказалось проблематично не только преподавателю, но и студенту. Преподаватели кафедры 
реализовывали онлайн обучение в форме конференций в СдО БГТУ, на платформах Microsoft Teams, Zoom. Данные платформы поддерживают видео связь, аудио связь, демонстрацию экрана (всего рабочего стола или одного приложения), использование виртуальной доски (Teams, Zoom), запись роликов. До и/или после практических занятий преподаватели обязательно оставляли время на общение со студентами, обсуждали трудности новой формы обучения. Следует отметить, что студенты, мотивированные к учебе, настойчиво осваивали материал и в принципе с задачей справились, несмотря на объективные трудности, но для многих отсутствие offline практических занятий и контакта с преподавателем привело к явным трудностям при решении некоторых классов задач, не умению логически рассуждать.

На вопрос в анкете о предпочтении проведения практических занятий (в формате online или offline) $80 \%$ студентов ответили, что ничего не заменит «живого» общения с преподавателем. А из платформ, которые использовали, выбирают Microsoft Teams или Zoom (88\%).

Рубежный контроль усвоения знаний (по темам) проводился аудиторно, в основном, в виде контрольных работ. Для экзаменов в свете соблюдения эпидемиологических требований была рекомендована письменная форма, что потребовало от преподавателя хорошо продумать содержание экзаменационных билетов. Для объективного оценивания уровня знаний студентов задачи, с одной стороны, должны быть узнаваемыми, а с другой стороны, предполагать и самостоятельную мыслительную деятельность студента.

\section{РЕЗУЛЬТАТЫ ИССЛЕДОВАНИЯ}

Каждый преподаватель в сложившихся непростых условиях последних лет накопил дополнительный опыт, который, несомненно, нужно использовать в дальнейшем.

Такой опыт привел, в частности, к следующим результатам:

- хорошо подготовленному изначально студенту с высоким уровнем мотивации удается преодолеть сложности удаленной формы обучения и продемонстрировать неплохие ответы на экзамене. Конечно, приходится поработать самому, значимость самостоятельной работы многократно возрастает. При умелой ее организации и использовании возможностей общения с преподавателем (пусть даже через информационно-коммуникационные средства, хотя большинство преподавателей проводили консультации в «живом» формате) можно добиться высокого уровня усвоения материала;

- на первый план при подготовке выходят такие качества студента, как умение и желание самостоятельно обрабатывать и усваивать предлагаемую информацию. Есть приятные «сюрпризы», когда на экзамене хочется сказать студенту о его ответе: «Это лучше, чем можно было ожидать». Кстати, среди таких «средних» студентов много тех, кто длительно болел, был на карантине и при этом не потерял, а только приобрел желание учиться. Желание саморазвития, учение «для себя» иногда является гораздо более мотивирующим фактором, чем остальные;

- если у студента совсем слабая первоначальная подготовка, при этом еще и слабый уровень коммуникации с остальными студентами группы, то удаленная форма обучения является для него непосильной и часто приводит к «провалу» на экзамене. Такой студент не может продвинуться вперед при подготовке и вообще теряет мотивацию. Если такая проблема выявляется заранее, преподавателю можно попытаться (конечно, если инициативу проявляет сам студент) помочь обучающемуся организовать свою самостоятельную работу, провести несколько консультаций в обычном формате. По возможности такие консультации проводить нужно, и рубежный контроль в аудиториях, конечно, очень информативен. Многие студенты во время проведения удаленных занятий активны, стараются показать свое присутствие, однако в дальнейшем оказывается, что это лишь видимая сторона. На самом же деле уровень этих студентов настолько слаб, что материал совершенно не усваивается, и на экзамене результат оказывается неудовлетворительным.

Отметим, что удаленная форма проведения занятий и ее сочетание с «живым» форматом консультаций требует задействования всего потенциала методических и технических умений преподавателя, да и его физическая подготовка оказывается далеко не лишней, нагрузки очень высоки.

\section{ВЫВОДЫ И ОБСУЖДЕНИЕ}

Таким образом, в основе современных подходов к преподаванию должны лежать разумные сочетания традиционных и дистанционных методов обучения.

Что показало использование удаленного обучения? Оно еще раз подтвердило тот факт, что результат обучения зависит не только и не столько от формы преподнесения преподавателем материала, сколько от желания и возможности студента эту информацию усваивать. Пока есть возможность проводить занятия в обычном «живом» формате, необходимо заранее закладывать в студентах навыки самообразования, учить их организовывать свой труд, свое время, умение проявлять инициативу и принимать самостоятельные решения, воспитывать у студентов стремление к саморазвитию. При необходимости онлайн обучения педагог должен использовать все возможности, чтобы помочь студенту в учебном процессе, обеспечив ему требуемую поддержку в усвоении знаний. Такая стратегия сотрудничества должна быть направлена на сохранение и улучшение качества образования в непростой эпидемиологический период.

Таким образом, организовывая онлайн обучение, в качестве первоочередной задачи преподавателя на данном этапе представляется следующая: научить «учиться» в широком понимании этого слова (Пармузина, 2020). Даже, учитывая интенсивное развитие алгоритмов искусственного интеллекта, человек остается ведущей фигурой в области образования, особенно по фундаментальным наукам.

Для хороших студентов, заинтересованных в качестве своего образования и занимающихся студенческой научноисследовательской работой, информационные технологии необходимы и весьма полезны. Эти студенты по совету преподавателей знакомятся в интернете с современными прикладными разделами математики, например, теорией чисел, методами оптимизации, теорией рядов Фурье, теорией эллиптических кривыхи их приложениями в криптографии (Марчук \& Асмыкович, 2019), (Курмашев \& Асмыкович, 2020). В этом случае преподаватель в рамках дистанционного 
общения рассматривает полученные студентами решения и дает советы по их анализу и дальнейшим исследованиям, описывает новые математические объекты, которые надо рассмотреть студенту.

Понятно, что в связи с объективной необходимостью перехода к системе непрерывного образования роль дистанционного образования будет усиливаться. В условиях все возрастающего потока информации образование должно сопровождать человека всю жизнь. В данной ситуации в школе и университете важно заложить прочный фундамент знаний и заложить понимание о необходимости пополнять их в системе непрерывного образования.

\section{Список использованных источников}

1. Асмыкович И.К. ИКТ и современное образование. Теория и реальность. Наукова діяльність як шлях формування професійних компетентностей майбутнього фахівця (НПК-2019): матеріали Міжн.ї науково-практ.ї конф., 5-6 грудня 2019 р., м. Суми; у 2-х частинах. Суми: ФОП Цьома С.П., 2019. Ч. 1. С. 84-86.

2. Asmykovich I.K., Arhipenko O.A. Importance of mathematics for information technology specialists. Збірник наукових праць за матеріалами дистанційної всеукраїнської наукової конференції «Математика у технічному університеті XXI сторіччя», 15 - 16 травня, 2019 р. Донбаська державна машинобудівна академія, м. Краматорськ. Краматорськ: ДДМА, 2019. С. $132-134$.

3. Асмыкович И.К., Борковская И.М., Пыжкова О.Н. О роли математики в формировании творческих навыков студентов технических университетов. Науковий вісник Льотної академії. Серія: Педагогічні науки. Збірник наукових праць / Гол. ред. Т.С. Плачинда. Кропивницький: ЛА НАУ, 2019. Вип. 5. С. 29-33.

4. Асмыкович И.К., Ловенецкая Е.И. О методическом обеспечении курса "Математические основы криптографии» в Белорусском государственном технологическом университете. Науковий журнал ФІЗИКО-МАТЕМАТИЧНА ОСВITА Випуск 1(19), 2019. С. 18-23.

5. Асмыкович И.К., Пыжкова О.Н. Достоинства и недостатки электронного обучения при преподавании математики в техническом университете. Моделирование и конструирование в образовательной среде: сборник материалов $V$ Всероссийской (с межд. участием) научно-практ., методологической конф. для научно-педагогического сообщества/ под ред. И.А. Артемьева, В.О. Белевцовой, Н.Д. Дудиной. М.: Издательство ГБПОУ «Московский государственный образовательный комплекс», 2020. С. 40-44.

6. Гараев Т.К., Бабина С.В. Особенности организации дистанционного обучения математике в условиях распространения инфекции COVID-19. Заметки ученого, 2020. №10. C. 201-204.

7. Гончарова З.Г. Дистанционное обучение как инновационная модель преподавания математики в высшей школе. Педагогика и психология образования, 2019. № 4. С. 95-103.

8. Курмашев Д.Д., Асмыкович И.К. Анализ и обработка данных для построения графиков. Роль математики в становлении специалиста-2020. Мат-лы Межд. научно-практ. конф. Уфимский государственный нефтяной технический университет, 2020. С. 49-53.

9. Марчук К.С., Асмыкович И.К. Алгоритм создания электронной подписи на основе групп точек на эллиптической кривой. Молодежь и наука: актуальные проблемы фундаментальных и прикладных исследований: материалы II Всерос. нац. науч. конф. студентов, аспирантов и молодых ученых, Комсомольск-на-Амуре, 08-12 апреля 2019 г.: в 4 ч./ редкол.: Э. А. Дмитриев (отв. ред.) [и др.]. Комсомольск-на-Амуре: ФГБОУ ВО «КнАГУ», 2019. Ч. 2. С. 354-356.

10. О приоритетных направлениях научной, научно-технической и инновационной деятельности на 2021-2025 годы. Указ Президента Республики Беларусь 7 мая 2020 г. № 156 [Электронный ресурс]. Режим доступа: http://president.gov.by/ru/official_documents_ru/view/ukaz-156-ot-7-maja-2020-g-23556. Дата доступа: 17.08.2020.

11. Пармузина М.С. Некоторые вопросы организации занятий по математике со студентами технического вуза в условиях карантина. Современные проблемы науки и образования. 2020. № 5.; URL: http://scienceeducation.ru/ru/article/view?id=30231 (дата обращения: 08.03.2021).

12. Тестов В.А. Электронные технологии в обучении математике: проблема понимания. Информатизация образования и методика электронного обучения: материалы II Междунар. науч. конф. Красноярск, 25-28 сентября 2018 г.: в 2 ч. ч. 2/ под общ. ред. М. В. Носкова. Красноярск: Сиб. федер. ун-т, 2018. С. 285-290.

\section{References}

1. Asmykovich, I.K. (2019). IKT i sovremennoe obrazovanie [ICT and modern education. Theory and reality]. Teorija i real'nost'. Naukova dijal'nist' jak shljah formuvannja profesijnih kompetentnostej majbutn'ogo fahivcja (NPK-2019): materiali Mizhn.ï naukovo-prakt.ï konf., 5-6 grudnja 2019 r., m. Sumi; u 2-h chastinah. Sumi: FOP C'oma S.P. [in Russian].

2. Asmykovich, I.K. \& Arhipenko, O.A.(2019). Importance of mathematics for information technology specialists. Zbirnik naukovih prac' za materialami distancijnoï vseukraïns'koï naukovoï konferenciï «Matematika u tehnichnomu universiteti XXI storichchja», 15 - 16 travnja, 2019 r. Donbas'ka derzhavna mashinobudivna akademija, m. Kramators'k. Kramators'k: DDMA.

3. Asmykovich, I.K., Borkovskaja, I.M. \& Pyzhkova, O.N. (2019). O roli matematiki v formirovanii tvorcheskih navykov studentov tehnicheskih universitetov [On the role of mathematics in the formation of creative skills of students of technical universities]. Naukovij visnik L'otnoï akademiï. Serija: Pedagogichni nauki. Zbirnik naukovih prac' / Gol. red. T.S. Plachinda. Kropivnic'kij: LA NAU. Vip. 5 [in Russian].

4. Asmykovich, I.K. \& Loveneckaja, E.I. (2019). O metodicheskom obespechenii kursa «Matematicheskie osnovy kriptografii» v Belorusskom gosudarstvennom tehnologicheskom universitete [On the methodological support of the course "Mathematical Foundations of Cryptography" at the Belarusian State Technological University]. Naukovij zhurnal FIZIKO-MATEMATICHNA OSVITA Vipusk 1(19) [in Russian].

5. Asmykovich, I.K. \& Pyzhkova, O.N. (2020). Dostoinstva i nedostatki jelektronnogo obuchenija pri prepodavanii matematiki v tehnicheskom universitete [Advantages and disadvantages of e-learning in teaching mathematics at a technical university]. Modelirovanie i konstruirovanie v obrazovatel'noj srede: sbornik materialov V Vserossijskoj (s mezhd. uchastiem) nauchno- 
prakt., metodologicheskoj konf. dlja nauchno-pedagogicheskogo soobshhestva/ pod red. I.A. Artem'eva, V.O. Belevcovoj, N.D. Dudinoj. M.: Izdatel'stvo GBPOU «Moskovskij gosudarstvennyj obrazovatel'nyj kompleks» [in Russian].

6. Garaev, T.K. \& Babina, S.V. (2020). Osobennosti organizacii distancionnogo obuchenija matematike $v$ uslovijah rasprostranenija infekcii COVID-19 [Features of the organization of distance learning mathematics in the context of the spread of COVID-19 infection]. Zametki uchenogo. no.10 [in Russian].

7. Goncharova, Z.G. (2019). Distancionnoe obuchenie kak innovacionnaja model' prepodavanija matematiki v vysshej shkole [Distance learning as an innovative model of teaching mathematics in higher education]. Pedagogika i psihologija obrazovanija, no. 4 [in Russian].

8. Kurmashev, D.D. \& Asmykovich, I.K. (2020). Analiz i obrabotka dannyh dlja postroenija grafikov [Analyzing and processing data for graphing]. Rol' matematiki v stanovlenii specialista-2020. Mat-ly Mezhd. nauchno-prakt. konf. Ufimskij gosudarstvennyj neftjanoj tehnicheskij universitet [in Russian].

9. Marchuk, K.S. \& Asmykovich, I.K. (2019). Algoritm sozdanija jelektronnoj podpisi na osnove grupp tochek na jellipticheskoj krivoj [Algorithm for creating an electronic signature based on groups of points on an elliptic curve]. Molodezh' i nauka: aktual'nye problemy fundamental'nyh i prikladnyh issledovanij: materialy II Vseros. nac. nauch. konf. studentov, aspirantov i molodyh uchenyh, Komsomol'sk-na-Amure, 08-12 aprelja 2019 g.: $\vee 4$ ch./ redkol.: Je. A. Dmitriev (otv. red.) [i dr.]. Komsomol'sk-na-Amure: FGBOU VO «KnAGU» [in Russian].

10. O prioritetnyh napravlenijah nauchnoj, nauchno-tehnicheskoj i innovacionnoj dejatel'nosti na 2021-2025 gody [On priority areas of scientific, scientific, technical and innovative activities for 2021-2025]. Ukaz Prezidenta Respubliki Belarus' 7 maja 2020 g. no. 156 [Jelektronnyj resurs]. Rezhim dostupa: http://president.gov.by/ru/official_documents_ru/view/ukaz-156-ot7-maja-2020-g-23556. Data dostupa: 17.08 .2020 [in Russian].

11. Parmuzina, M.S. (2020). Nekotorye voprosy organizacii zanjatij po matematike so studentami tehnicheskogo vuza v uslovijah karantina [Some issues of organizing mathematics classes with students of a technical university in quarantine]. Sovremennye problemy nauki i obrazovanija. No. 5.; URL: http://science-education.ru/ru/article/view?id=30231 (data obrashhenija: 08.03.2021) [in Russian].

12. Testov, V.A. (2018). Jelektronnye tehnologii v obuchenii matematike: problema ponimanija [Electronic technologies in teaching mathematics: the problem of understanding]. Informatizacija obrazovanija i metodika jelektronnogo obuchenija: materialy II Mezhdunar. nauch. konf. Krasnojarsk, 25-28 sentjabrja 2018 g.: v 2 ch. Ch. 2/ pod obshh. red. M. V. Noskova. Krasnojarsk: Sib. feder. un-t [in Russian].

\section{ABOUT THE EXPERIENCE OF TEACHING MATHEMATICS FOR ENGINEERING SPECIALTIES IN THE FRAMEWORK OF DISTANCE LEARNING I.K. Asmykovich, O.N. Pyzhkova, I.M. Borkovskaya Belarusian State Technological University, Belarus}

Abstract.

Formulation of the problem. The article discusses the problem of ensuring the quality of mathematical education in modern conditions. To solve this problem, it is necessary to improve both the forms and methods of teaching, and the organization of the educational process as a whole. At present, when teaching is complicated by the problem of complying with epidemiological requirements in connection with the spread of COVID-19 infection, it is necessary to make optimal use of all opportunities to ensure the proper level of mathematical training of future engineers.

Materials and methods. To solve the problem, the experience of teaching mathematical disciplines at the Department of Higher Mathematics of the Belarusian State Technological University using both traditional and information and communication technologies is analyzed. The results of a survey conducted among students of the Faculty of Technology of Organic Substances of BSTU are used. Analyzed modern publications on distance learning mathematics.

Results. The analysis of the state of teaching mathematics for students of engineering specialties in the Republic of Belarus is carried out. The issue of the use of classical and information and communication educational technologies in modern conditions is studied on the example of teaching mathematical disciplines, as well as the possibilities of online learning using the platforms LMS Moodle, Microsoft Teams, Zoom, etc. The disadvantages and advantages of distance learning are discussed.

Conclusions. Optimal for ensuring the quality of mathematical education in modern conditions is a combination of classical approaches to teaching using information and communication technologies. The degree of assimilation of knowledge depends not so much on the form of presentation of the material by the teacher, but on the student's motivation to study the subject. It is necessary to instill in students the skills of self-education, self-organization, independent decision-making, to instill in students the desire for self-development. Online learning should use all the opportunities for learning and building feedback with students in order to maintain the quality of education in a difficult epidemiological period.

Key words: mathematics, teaching methods, classical approach, information and communication technologies.

\section{(cc) BY-NC-SA}

This work is licensed under Creative Commons Attribution-NonCommercial-ShareAlike 4.0 International License. 